\title{
Clinical efficacy of different marginal forms of endocrowns: study protocol for a randomized controlled trial
}

\author{
Jieli Sun, Wenhao Ruan, Jiahui He, Xiaoyu Lin, Bowen Ci, Siye Yin and Wenjuan Yan * (D)
}

\begin{abstract}
Background: After root canal treatment, most tooth defects need to be restored. Onlay restoration is widely used to restore dental defects. Endocrown is a new type of onlay; however, dentists have yet to obtain a full understanding of the clinical effects of marginal forms of endocrowns. Here, we present a multicenter protocol to compare the clinical efficacy of two marginal forms (flat and 90-degree shoulder) for tooth restoration. The efficacy will be evaluated by marginal fit, marginal discoloration, and integrity of restoration.

Methods: The proposed flat and 90-degree shoulder marginal endocrown assessment trial is an open-label, parallelgroup, multicenter randomized controlled trial involving two hospitals. A total of 200 patients will be included in this trial, and the following patient inclusion criteria will be applied: good oral hygiene habits, no periodontal diseases, receipt of standard root canal treatment, and need for endocrown restoration. Patients will be enrolled after providing signed informed consent and will be divided into two groups (flat and 90-degree shoulder endocrown) in accordance with a random number table. Treatment allocation will be balanced (1:1). Endocrowns will be cemented by dual-cured luting composite. Clinical evaluations will be performed at baseline and at 24 months after treatment in accordance with modified US Public Health Service criteria by two independent evaluators. The primary outcome will be marginal fit; secondary outcome measures will include debonding, marginal discoloration, and integrity of restoration. All acquired data will be analyzed by an independent statistician. Wilcoxon one-sample tests will be used for intra-group comparisons, and Wilcoxon two-sample tests will be used for inter-group comparisons. The Bonferroni method will be used to correct for multiple comparisons, and hierarchical logistic regression will be applied to determine central effects.
\end{abstract}

Discussion: The results of this trial will provide a clinical basis for clinicians to restore teeth by endocrowns and to improve long-term restoration for patients.

Trial registration: ClinicalTrials.gov identifier: NCT03398395. Registered on 12 January 2018.

Keywords: Dental defect, Endocrown, Margin, CAD/CAM, Dental restoration, Root canal treatment

\section{Background}

Pulpal and periapical diseases are the main causes of tooth loss. Root canal treatment (RCT) is the only effective means for treating these diseases. However, in the absence of coronal restoration, failure of RCT is commonly seen. Contamination of the root canal system by saliva, which is referred to as "coronal leakage" or

\footnotetext{
* Correspondence: 645613053@qq.com

Department of Conservative and Endodontic Dentistry, Nanfang Hospital, Southern Medical University, 1838 N Guangzhou Rd, Guangzhou 510515,
} China

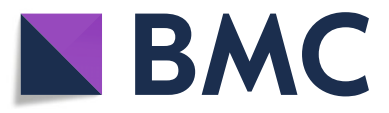

(c) The Author(s). 2019 Open Access This article is distributed under the terms of the Creative Commons Attribution 4.0 International License (http://creativecommons.org/licenses/by/4.0/), which permits unrestricted use, distribution, and reproduction in any medium, provided you give appropriate credit to the original author(s) and the source, provide a link to the Creative Commons license, and indicate if changes were made. The Creative Commons Public Domain Dedication waiver (http://creativecommons.org/publicdomain/zero/1.0/) applies to the data made available in this article, unless otherwise stated. coronal microleakage", is a potential cause of endodonteeth are vulnerable to fracture after RCT, the main reasons for which are as follows: (1) Dentin regeneration ceases once secondary dentin and tertiary dentin are interrupted. (2) In some cases, considerable loss of dental tissues has occurred because of deep caries, abrasion, or trauma [2]. (3) Tooth structure is weakened during RCT. As treated teeth are prone to fracture, especially in the coronal region of the posterior teeth, it is very important to restore the teeth within a certain time period 
after RCT. Moreover, coronal restoration can prevent reinfection of the root canal system or periapical area.

There are many ways to restore teeth after RCT, such as composite resin direct filling, inlay restoration, onlay restoration, full crown restoration, and post-core crown restoration [3]. In onlay restoration, one or more cusps of tooth are covered. This technique not only provides superior aesthetics but also minimizes the loss of healthy tooth tissue, making it an attractive treatment choice for posterior teeth with extensive cavities due to caries [4]. Moreover, by covering more than one tooth cusp, onlay provides a favorable distribution of stress, reducing the fracture risk of tooth or restoration or both. Ceramic onlay restoration showed promising results, yielding a $92.5 \%$ success rate, in a 4-year investigation of extensively restored, endodontically treated molars [5]. These observations suggest that onlay restorations are an optimal approach to restoring posterior teeth after RCT.

Endocrown is a new type of onlay with a retainer in the pulp cavity $[6,7]$. It consists of a cervical margin in the form of a butt joint and a preparation of the pulp chamber. The endurance and stability of the restoration derive from the adhesion of cementation and increased stress sharing as well as the interface provided by the pulp cavity retainer [8]. This restoration method is not only effective for preserving residual tooth tissue but also suitable for severely damaged molars or premolars after dental pulp treatment [9]. Compared with postcore crown techniques, endocrown restoration is simpler because of the core-crown integrity; furthermore, no post is needed, reducing the risk of root fracture [10]. Post-core crown restoration is aimed at strengthening residual dental hard tissue and replacing missing dental tissue. The resistance of the tooth cervix is not enhanced, and the post only provides the retaining force for the crown [11]. Furthermore, post-core crown restoration can present additional risks, such as canal perforation and root fracture. Full crown restoration is also widely performed. A finite element analysis of a full crown and endocrown revealed that the endocrown was superior to the traditional full crown [12]. According to biomechanics, the strength of the dental tissue depends on the amount of dental hard tissue and its internal strength and anatomical characteristics. The characteristics of dental tissue are affected by caries, the preparation of the cavity, the path of access to the canals, and the enlargement of the root canal. However, Dietschi et al. showed that the effects of endodontic treatment on dental biomechanical properties are limited [13]. A three-dimensional finite element study showed that the stress distribution on enamel, dentin, and adhesive surface was smaller for endocrown than for all-porcelain onlay and traditional full crown $[14,15]$. In addition, several experiments showed that endocrown had greater fracture resistance than traditional completed crown [14-16]. A retrospective study of endocrown restorations reported a clinical success rate of 94-100\% [17] and demonstrated that the retention effect of endocrown restoration was superior to that of traditional full crown restoration. Endocrown restoration can preserve residual tooth tissue to a greater extent than can other restoration methods. It is especially useful for teeth with a low occlusogingival distance that have insufficient retention ability for a full crown.

Studies have shown that the type of marginal form has a significant effect on the prognosis of prostheses after RCT and restoration with full crowns [18-20]. The study by Taha et al. showed that adding a 1-mm shoulder finish line can increase the endocrown's fracture resistance. However, further investigations, especially on fatigue behavior, are needed [21]. The restoration ability of endocrowns is affected by the bonding surface and the amount of residual tooth tissue [22]. The enamel layer distribution of the teeth bases, which determines the composition of the bonding surface as well as the residual amount of dental tissue, varies according to the preparation of the different marginal forms of endocrowns. A flat endocrown shows more residual tooth tissue and less bonding area, whereas a 90-degree shoulder endocrown leads to a larger bonding area and less residual tooth tissue. Whether there is a significant difference in restorative effect between these two forms is difficult to predict. Therefore, two common marginal forms of endocrowns will be designed in this study to observe their restoration effects (Fig. 1).

$\mathrm{CAD} / \mathrm{CAM}$ is a type of computer-aided design and manufacturing software. The dental CAD/CAM system is used to collect imaging data of digital impressions through a built-in camera and does not require the intermediate links of traditional restoration systems, such as preparing molds and fillings. Therefore, this system can avoid possible errors during milling with numerical control machine tools. Because of its advantages in precision and clinical restoration, it is increasingly favored by patients and dentists [23, 24]. In recent studies, the system was used to successfully prepare complex prostheses that cannot be produced by traditional methods and was found to significantly shorten the production time of restorations [25].

Along with the rapid innovations in digital dentistry, additional chair-side CAD/CAM materials have been developed. According to the latest classification system, allceramic and ceramic-like restorative materials can be categorized into three groups, depending on the phase or phases present in their chemical composition: (1) glassmatrix ceramics, (2) polycrystalline ceramics, and (3) resin-matrix ceramics. All three types offer good aesthetic performance, mechanical properties, and biocompatibility 


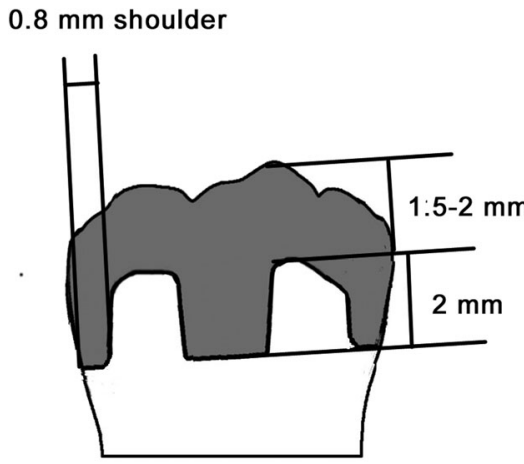

A

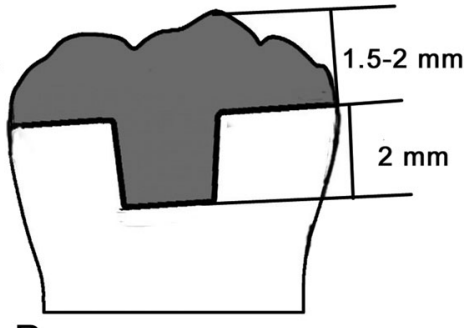

B

Fig. 1 Schematic representations of the two marginal forms of endocrown. A. Ninety-degree shoulder endocrown (intervention group). B. Flat endocrown (control group).

[26, 27]. Glass-matrix ceramics are non-metallic inorganic ceramic materials that contain a glass phase and a dispersed crystalline phase (crystals) and are divided into three subgroups: feldspathic ceramics, synthetic ceramics, and glass-infiltrated ceramics. Synthetic ceramics can effectively prevent the expansion of cracks and improve the strength and cutting performance of the materials because of the greater presence of the crystalline phase than of the glass phase. Leucite-reinforced lithium disilicate and zirconia-reinforced lithium silicate ceramics are representatives of synthetic glass ceramics. Lithium disilicate ceramic (IPS e.max CAD, Ivoclar Vivadent, Amherst, NY, USA) is composed of about 70 vol.\% of crystalline phase incorporated in the glassy matrix. The intermediate crystalline phase or "blue" state has $130 \pm 30 \mathrm{MPa}$ flexural strength, and the final flexural strength can reach $360 \pm$ $60 \mathrm{MPa}$. It is widely used in clinical practice because of its good flexural strength and shade; however, it is also disadvantageous because the $15-20 \%$ contraction of the material after polymerization may lead to a reduction in the density between the onlay and teeth during the second sintering process [28]. Zirconia-enhanced lithium silicate glass ceramic (VITA SUPRINITY, VITA Zahnfabrik, Bad Säckingen, Germany) contains lithia (15-21 wt.\%) and zirconia (8-12 wt.\%) (about 10 times more zirconium dioxide than in traditional CAD/CAM glass ceramic). Its flexural strength can reach $450 \mathrm{MPa}$ after glazing. Its ultrafine $(0.5-\mu \mathrm{m})$ granules guarantee a homogeneous material structure to avoid polymerization shrinkage during the second sintering step. In addition, it has good emulsion fluorescence, which ensures an improved clinical polishing effect [29]. Experimental studies showed that VITA SUPRINITY had greater fracture toughness, flexural strength, elastic modulus, and hardness than disilicate glass ceramics.

Despite its advantages, VITA SUPRINITY has seldom been used in the design of different marginal forms of endocrowns. Therefore, we will use it as the experimental material in this study based on the dental CAD/CAM system.

\section{Methods and design Hypothesis}

For this study, we hypothesize that the restorative effect of the 90-degree shoulder endocrown will be superior to that of the flat endocrown restoration.

\section{Objective}

The objective is to compare differences between the two marginal forms of endocrowns (i.e., 90-degree shoulder and flat) by assessing the firmness, comfort, and durability of dental restorations after RCT using VITA SUPRINITY blocks designed and manufactured using a chairside CEREC CAD/CAM system (Dentsply Sirona, Bensheim, Germany).

\section{Methods}

This is a multicenter, randomized, open-label superiority trial with two balanced parallel arms. The participants will be recruited from the Departments of Conservative and Endodontic Dentistry in Nanfang Hospital of Southern Medical University and the Guanghua School of Stomatology of Sun Yat-sen University. The schedule of enrollment, interventions and assessments is showed in Fig 2.

\section{Inclusion criteria}

1. The patient is healthy and is $18-60$ years old and has molar teeth and tooth root apex without evident damage and no root fracture, as determined by $\mathrm{x}$-ray.

2. The patient has three or four walls of intact tooth tissue after complete root canal therapy.

3. The patient has good oral hygiene.

4. The patient has signed an informed consent form. 


\begin{tabular}{|c|c|c|c|c|c|}
\hline & \multicolumn{5}{|c|}{ STUDY PERIOD } \\
\hline TIMEPOINT** & $\begin{array}{c}\text { Pre- } \\
\text { treatment }\end{array}$ & $\begin{array}{c}\text { Post- } \\
\text { treatment }\end{array}$ & $\begin{array}{l}\text { 6-month } \\
\text { follow-up }\end{array}$ & $\begin{array}{l}\text { 12-month } \\
\text { follow-up }\end{array}$ & $\begin{array}{l}\text { 24-month } \\
\text { follow-up }\end{array}$ \\
\hline \multicolumn{6}{|l|}{ ENROLMENT: } \\
\hline \multirow[b]{3}{*}{ Baseline data collection } & $X$ & & & & \\
\hline & $\mathrm{X}$ & & & & \\
\hline & $\mathrm{X}$ & & & & \\
\hline Randomize subjects & $X$ & & & & \\
\hline Allocation & $X$ & & & & \\
\hline \multicolumn{6}{|l|}{ INTERVENTIONS: } \\
\hline \multicolumn{6}{|l|}{$\begin{array}{r}90 \text { degree shoulder } \\
\text { endocrown }\end{array}$} \\
\hline \multicolumn{6}{|l|}{ Flat endocrown } \\
\hline \multicolumn{6}{|l|}{ ASSESSMENTS: } \\
\hline \multirow[t]{2}{*}{ Primary outcome } & & $\mathrm{X}$ & $\mathrm{X}$ & $\mathrm{X}$ & $\mathrm{X}$ \\
\hline & & $\mathrm{X}$ & $\mathrm{X}$ & $X$ & $X$ \\
\hline
\end{tabular}

Fig. 2 SPIRIT (Standard Protocol Items: Recommendations for Interventional Trials) Figure

5. The patient is not participating in any other clinical trial.

6. The patient has received a class A assessment according to the modified US Public Health Service (USPHS) criteria for marginal adaptation after restoration.

\section{Exclusion criteria}

1. Obvious destruction of the apical tissue or presence of large cysts or both

2. Severe periodontitis

3. Oral malignant tumor(s)

4. Undergoing radiotherapy

5. Pregnancy

6. Mental illness or systemic diseases

7. Incapable of self-care

8. Unsuitable for the trial as deemed by the researchers

\section{Dropout criteria}

1. Poor clinical compliance

2. Voluntary withdrawal from the trial by the patient
According to the software nQuery Advisor + nTerim 3.0, a sample size of 160 patients (80 for each group) should be recruited [30]. To allow for $20 \%$ attrition, the recruitment sample size for this trial will be 200 patients (100 in each group).

Upon fulfilment of the selection criteria, 200 eligible participants will be randomly divided into intervention and control groups in a 1:1 allocation ratio. Randomization will be performed in accordance with a random list of numbers generated by the Department of Biomedical Statistics of Southern Medical University. Five dentists will participate in this study and all of them will have received standardized training in endocrown restoration before the study begins. The number of cases assigned to each dentist is unknown and will vary because of factors outside the control of the study. These five dentists will not be involved in observations or data collection during the clinical evaluations.

\section{The intervention group}

The intervention group will receive 90-degree shoulder endocrown restoration. The restoration will be completed by the following steps: (1) All decayed or damaged areas of the tooth will be removed, and occlusal 
anatomical reduction of $2.0 \mathrm{~mm}$ will be performed to form a 90-degree rounded shoulder margin. Guttapercha will be removed to a depth not exceeding $2 \mathrm{~mm}$ and sealed with composite resin. The undercuts of the tooth cavity will be blocked out with a nano-hybrid composite resin, which will serve as a base material. A 2- to 5-degree divergence of the vertical walls will be prepared with a conical flat-end diamond bur. (2) A chair-side CEREC CAD/CAM system will be used to mill VITA SUPRINITY blocks to obtain the prosthesis. (3) Cementation, occlusion adjustment, and polishing will be performed. (4) Patients whose affected tooth receives a class A assessment according to the modified USPHS criteria of marginal adaptation will be included in this trial.

\section{The control group}

The control group will be treated with flat endocrown restoration. In the first step of the restoration, all of the decayed or damaged areas of the tooth will be removed, and occlusal flat reduction of $1.5-2.0 \mathrm{~mm}$ will be achieved. The subsequent steps will be the same as those for the intervention group.

\section{Outcome measures}

Clinical evaluations will be performed at baseline and at 24 months after treatment according to modified USPHS criteria by two independent evaluators (Table 1) [31-34]. The evaluators will complete a standardized training program before the experiment begins. If two evaluators present inconsistent evaluations during the study, a third evaluator will perform an evaluation, and the concurring evaluations from two evaluators will be used for analysis.

\section{Data collection}

The investigators will use a case report form (CRF) to collect data for the outcome analysis. The CRF includes demographic data, oral habits, medical history, and adverse events. To protect the privacy of patients, the patients will be registered with the first letters of their full name on the form. A clinical researcher will visit each center to inspect the acquired data and assess data quality by comparing the data with the medical records. The data will be entered twice into a database by designated operators and inspected by a data manager.

\section{Statistical methods Basic principles}

The data will be analyzed by an independent statistician. All statistical tests will be two-tailed. A $P$ value of less than 0.05 will be the level of significance, and $95 \%$ confidence intervals will be calculated. Parametric methods will be considered first. Data that do not meet or cannot be transformed to meet parametric assumptions will be analyzed by non-parametric methods.

\section{Primary outcome analysis}

Wilcoxon one-sample tests will be used for intra-group comparisons, and Wilcoxon two-sample tests will be used for inter-group comparisons. The Bonferroni method will be used for multiple comparisons, and hierarchical logistic regression will be used to detect central effects.

\section{Secondary outcome analysis}

For intra-group comparisons, paired $t$ tests or Wilcoxon one-sample tests will be used for quantitative variables, and McNemar tests will be used for qualitative variables. For inter-group comparisons, quantitative variables will be analyzed by one-way analysis of variance (more than two groups) and two-sample $t$ tests (two groups) or by non-parametric methods. Qualitative variables will be analyzed by Pearson's chi-squared tests. Non-parametric data will be analyzed by the Kruskal-Wallis test.

Table 1 Modified USPHS criteria

\begin{tabular}{lll}
\hline Category & Rating & Criteria \\
\hline Marginal adaptation & A & Probe, does not catch, smooth margin interface \\
& B & Probe catches at single spots, slight roughness \\
C & P & Probe catches under 50\% of margin length \\
Marginal discoloration & A & Probe catches at/over $50 \%$ of margin length \\
& B & No discoloration on the margin \\
Integrity of restoration & C & Discoloration has penetrated the margin in pulp direction \\
& A & Completely intact \\
& B & Crack apparent on transillumination \\
C & Fracture observable \\
& D & Crown lost(state at which interface debond occurred) \\
\hline
\end{tabular}




\section{Discussion}

This trial will help clinicians provide their clients with evidence-based options regarding marginal forms of endocrowns. However, owing to limitations associated with dental defects after RCT, the 90-degree shoulder endocrown is not suitable for all tooth restorations. Therefore, the selection of marginal forms should be based on the conditions of the dental defects.

This randomized clinical trial (see SPIRIT check list the Additional file 1) may lead to an improvement in the survival rate of restorations for patients. For researchers, it may provide input for further research concerning the marginal forms of endocrowns.

\section{Trial status}

This trial is in the process of recruiting participants.

\section{Additional file}

Additional file 1: SPIRIT (Standard Protocol Items: Recommendations for Interventional Trials) 2013 Checklist: Recommended items to address in a clinical trial protocol and related documents*. (DOC $135 \mathrm{~kb}$ )

\section{Abbreviations}

CAD/CAM: Computer-aided design/computer-aided manufacture; CRF: Case report form; RCT: Root canal treatment; USPHS: US Public Health Service

\section{Authors' contributions}

JLS drafted the manuscript. WHR participated in the design of the study. $J H H$ performed the statistical analysis. XYL and BWC recruited participants. SYY collected case data. WJY conceived the study, participated in its design and coordination, and helped draft the manuscript. All authors read and approved the final manuscript.

\section{Funding}

This trial is funded by a grant from Southern Medical University (LC2016PY023).

\section{Availability of data and materials}

All data are fully available without restriction.

\section{Ethics approval and consent to participate}

This trial was approved by the medical ethics committee of Nanfang Hospital, Southern Medical University. The study protocol has been registered on ClinicalTrials.gov (NCT03398395). The purpose, procedures, and potential risks of the trial will be clearly explained to the participants. All participants will provide written informed consent before joining the trial.

\section{Competing interests}

The authors declare that they have no competing interests.

Received: 26 February 2018 Accepted: 17 June 2019

Published online: 24 July 2019

\section{References}

1. Skupien JA, Cenci MS, Opdam NJ, Kreulen CM, Huysmans MC, Pereira-Cenci T. Crown vs. composite for post-retained restorations: a randomized clinical trial. J Dent. 2016:48:34-9.

2. Schwartz RS, Robbins JW. Post placement and restoration of endodontically treated teeth: a literature review. J Endod. 2004:30:289-301 [PubMed].

3. Rocca GT, Krejci I. Crown and post-free adhesive restorations for endodontically treated posterior teeth: from direct composite to endocrowns. Eur J Esthet Dent. 2013;8:156-79 [PubMed].
4. Yamanel K, Caglar A, Gülsahi K, Ozden UA. Effects of different ceramic and composite materials on stress distribution in inlay and onlay cavities: 3-D finite element analysis. Dent Mater J. 2009;28:661-70.

5. Ozyoney G, Yan Koğlu F, Tağtekin D, Hayran O. The efficacy of glass-ceramic onlays in the restoration of morphologically compromised and endodontically treated molars. Int J Prosthodont. 2013;26:230-4.

6. Leonard DL. Commentary: the endocrown: an alternative approach for restoring extensively damaged molars. J Esthet Restor Dent. 2013:25:391.

7. Fages M, Bennasar B. The endocrown: a different type of all-ceramic reconstruction for molars. J Can Dent Assoc. 2013:79:d140 [PubMed].

8. Lander E, Dietschi D. Endocrowns: a clinical report. Quintessence Int. 2008; 39:99-106 [PubMed].

9. Sevimli G, Cengiz S, Oruc MS. Endocrowns: review. J Istanb Univ Fac Dent. 2015:49:57-63.

10. Biacchi GR, Basting RT. Comparison of fracture strength of endocrowns and glass fiber post-retained conventional crowns. Oper Dent. 2012;37:130-6.

11. Mohammadi N, Kahnamoii MA, Yeganeh PK, Navimipour EJ. Effect of fiber post and cusp coverage on fracture resistance of endodontically treated maxillary premolars directly restored with composite resin. J Endod. 2009;35: 1428-32.

12. Dejak B, Młotkowski A. 3D-Finite element analysis of molars restored with endocrowns and posts during masticatory simulation. Dent Mater. 2013;29: e309-17.

13. Dietschi D, Duc O, Krejci I, Sadan A. Biomechanical considerations for the restoration of endodontically treated teeth: a systematic review of the literature--Part 1. Composition and micro- and macrostructure alterations. Quintessence Int. 2007;38:733-43 [PubMed].

14. Lin $\mathrm{CL}$, Chang $\mathrm{YH}, \mathrm{Pa} \mathrm{CA}$. Estimation of the risk of failure for an endodontically treated maxillary premolar with MODP preparation and CAD/CAM ceramic restorations. J Endod. 2009:35:1391-5.

15. Lin CL, Chang YH, Chang CY, Pai CA, Huang SF. Finite element and Weibull analyses to estimate failure risks in the ceramic endocrown and classical crown for endodontically treated maxillary premolar. Eur J Oral Sci. 2010; 118:87-93.

16. Guo J, Wang Z, Li X, Sun C, Gao E, Li H. A comparison of the fracture resistances of endodontically treated mandibular premolars restored with endocrowns and glass fiber post-core retained conventional crowns. J Adv Prosthodont. 2016:8:489-93.

17. Sedrez-Porto JA, Rosa WL, da Silva AF, Münchow EA, Pereira-Cenci T. Endocrown restorations: a systematic review and meta-analysis. J Dent. 2016;52:8-14.

18. Kierklo A, Tribiłło R, Walendziuk A, Stokowska W. The influence of cervical lesion on the stress state and strength of tooth with occlusal restoration: a numerical model study. Rocz Akad Med Bialymst. 2002:47:95-104 [PubMed].

19. Juloski J, Radovic I, Goracci C, Vulicevic ZR, Ferrari M. Ferrule effect: a literature review. J Endod. 2012;38:11-9 [PubMed]

20. Pierrisnard L, Bohin F, Renault $\mathrm{P}$, Barquins M. Corono-radicular reconstruction of pulpless teeth: a mechanical study using finite element analysis. J Prosthet Dent. 2002:88:442-8.

21. Taha D, Spintzyk S, Schille C, Sabet A, Wahsh M, Salah T, et al. Fracture resistance and failure modes of polymer infiltrated ceramic endocrown restorations with variations in margin design and occlusal thickness. J Prosthodont Res. 2018:62:293-7 [PubMed].

22. Vianna A, Prado C, Bicalho AA, Pereira R, Neves F, Soares CJ. Effect of cavity preparation design and ceramic type on the stress distribution, strain and fracture resistance of CAD/CAM onlays in molars. J Appl Oral Sci. 2018;26: e20180004 [PubMed].

23. Otto T, Mörmann WH. Clinical performance of chairside CAD/CAM feldspathic ceramic posterior shoulder crowns and endocrowns up to 12 years. Int J Comput Dent. 2015;18:147-61 [PubMed].

24. Bernhart J, Bräuning A, Altenburger MJ, Wrbas KT. Cerec3D endocrowns--twoyear clinical examination of CAD/CAM crowns for restoring endodontically treated molars. Int J Comput Dent. 2010;13:141-54 [PubMed]

25. Van Noort R. The future of dental devices is digital [J]. Dent Mater. 2012;28: 3-12.

26. Gracis S, Thompson VP, Ferencz JL, Silva NR, Bonfante EA. A new classification system for all-ceramic and ceramic-like restorative materials. Int J Prosthodont. 2015:28:227-35.

27. El-Damanhoury HM, Haj-Ali RN, Platt JA. Fracture resistance and microleakage of endocrowns utilizing three CAD-CAM blocks. Oper Dent. 2015:40:201-10. 
28. Höland W, Rheinberger V, Apel E, Hoen CV. Principles and phenomena of bioengineering with glass-ceramics for dental restoration. J Eur Ceram Soc 2007;27:1521-6.

29. Elsaka SE, Elnaghy AM. Mechanical properties of zirconia reinforced lithium silicate glass-ceramic. Dent Mater. 2016;32:908-14.

30. Kolassa JE. A comparison of size and power calculations for the Wilcoxon statistic for ordered categorical data. Stat Med. 1995;14:1577-81 [PubMed].

31. Priyadarshini BI, Jayaprakash $T$, Nagesh B, Sunil CR, Sujana V, Deepa VL. Oneyear comparative evaluation of Ketac Nano with resin-modified glass ionomer cement and Giomer in noncarious cervical lesions: a randomized clinical trial. J Conserv Dent. 2017;20:204-9.

32. Heymann HO, Sturdevant JR, Brunson WD, Wilder AD, Sluder TB, Bayne SC. Twelve-month clinical study of dentinal adhesives in class $V$ cervical lesions. J Am Dent Assoc. 1988;116:179-83.

33. Barnes DM, Blank LW, Gingell JC, Gilner PP. A clinical evaluation of a resinmodified. Glass ionomer restorative material. J Am Dent Assoc. 1995;126: $1245-53$.

34. Cvar JF, Ryge G. Reprint of criteria for the clinical evaluation of dental restorative materials. 1971. Clin Oral Investig. 2005;9:215-32.

\section{Publisher's Note}

Springer Nature remains neutral with regard to jurisdictional claims in published maps and institutional affiliations.

Ready to submit your research? Choose BMC and benefit from:

- fast, convenient online submission

- thorough peer review by experienced researchers in your field

- rapid publication on acceptance

- support for research data, including large and complex data types

- gold Open Access which fosters wider collaboration and increased citations

- maximum visibility for your research: over $100 \mathrm{M}$ website views per year

At BMC, research is always in progress.

Learn more biomedcentral.com/submissions 